\title{
VARIANTES, ESTRATOS DE INTERVENCIÓN Y TEXTOS EN EL MANUSCRITO AUTÓGRAFO DE LA BUENA GUARDA Y LA ENCOMIENDA BIEN GUARDADA
}

\author{
Stefania Capoia ${ }^{1}$
}

Cita Recomendada: Stefania Capoia, «Variantes, estratos de intervención y textos en el manuscrito autógrafo de La buena guarda y La encomienda bien guardada", Anuario Lope de Vega. Texto, literatura, cultura, XX (2014), pp. 122-158.

DOI: <http://dx.doi.org/10.5565/rev/anuariolopedevega.90>

Fecha de recepción: 13-01-2014 / Fecha de aceptación: 24-01-2014

\section{RESUMEN}

En el presente trabajo estudio, analizo y clasifico las variantes y los estratos de intervención presentes en el manuscrito de La buena guarda y La encomienda bien guardada de Lope de Vega y defiendo la necesidad de afrontar la edición de la segunda versión de la obra, posibilidad hasta ahora desatendida por los editores modernos.

Palabras Clave: Lope de Vega; crítica textual; filología de autor; crítica genética; La encomienda bien guardada; La buena guarda; manuscrito autógrafo; variantes de autor.

\section{AbstRact}

In this article I study, analyze and classify the variant readings and the different layers of authorial intervention that appear in Lope de Vega's La buena guarda and La encomienda bien guardada manuscript. I contend that the second version of the work should be edited, a possibility thus far neglected by modern editors.

KeYwords: Lope de Vega; textual criticism; genetic criticism; La encomienda bien guardada; La buena guarda; autograph manuscript; authorial variants.

1 Estas páginas reproducen la sección relativa a los problemas textuales de la "tesi di Laurea» de Stefania Capoia dirigida por el prof. Marco Presotto y titulada Edición crítica de «La encomienda bien guardada” de Lope de Vega, que fue presentada en la Università Ca' Foscari de Venecia en el año 2005 (curso académico 2004-2005). Dichas páginas han sido revisadas, actualizadas y editadas para darles forma de artículo por Sònia Boadas, Daniel Fernández Rodríguez y Ramón Valdés. Desde la lectura de esta tesis de licenciatura, ha habido dos aportaciones esenciales: un artículo de Paloma Cuenca Muñoz [2006] y una edición en línea de Francisco Crosas [2009], que será también el editor de la obra cuando se publique la Parte XV de comedias a cargo de Prolope. Nota de los editores. 
$\mathrm{E}$ n el presente trabajo intento dar cuenta de los problemas textuales a los que deberá enfrentarse el editor de una obra de Lope de Vega Carpio, La buena guarda o La encomienda bien guardada, que se conserva en un manuscrito con unas particularidades muy interesantes para el estudio de los procesos creativos y los problemas narrativos que puede presentar la redacción de una pieza teatral. Echándole solo un primer y rápido vistazo al manuscrito, apreciaremos inmediatamente que contiene numerosas tachaduras y enmiendas que se identifican como intervenciones del mismo autor, además de unas grafías distintas que se insertan en los loci critici (los que están corregidos por Lope), o en lo que concierne al paratexto y todo lo que tiene que ver con la puesta en escena de la comedia.

Cuando, en el curso 2004-2005, me enfrenté a la edición crítica del texto, todavía no existía una edición definitiva y fiable que tuviera en cuenta todas las características del manuscrito ni que intentara establecer la sucesión cronológica y la autoría de las distintas manos que intervinieron en su ejecución. Tras estudiar detenidamente primero la versión en microfilm, pude luego examinar directamente el manuscrito del autor, conservado en la Biblioteca Nacional de España, lo que me permitió aclarar unos pasajes dudosos analizando las características caligráficas de las distintas manos, de las intervenciones y las cualidades de las tintas. Asimismo procedí con el cotejo de las dos impresiones antiguas de la Decimoquinta Parte, ambas de 1621.

EsTADO DE LA CUESTIÓN: LOS EDITORES MODERNOS

Se cuentan seis ediciones modernas: la edición de Juan Eugenio Hartzenbusch [1857], la de Marcelino Menéndez y Pelayo [1895], la de Eduardo Juliá Martínez [1934], la de Pilar Díez y Giménez Castellanos [1936], la de María del Carmen Artigas [1990 y 2002] y la más reciente en red de Francisco Crosas [2009], in fieri. ${ }^{2}$ En numerosas ocasiones estos editores y muchos estudiosos aluden a La buena guarda o La

2 La edición de María del Carmen Artigas fue primero su tesis doctoral [1990], que luego publicó en la Editorial Verbum [2002]. La edición de Francisco Crosas [2009] que se presenta en la red e in fieri, es en realidad una primera versión de la edición que finalmente publicará Prolope. Por último, recientemente ha aparecido una edición digital a cargo de David Guinart en la base de datos ARTELOPE, que sigue el texto de Menéndez Pelayo. 
encomienda bien guardada, ${ }^{3}$ como si se tratara de una sola pieza de título alternativo, como ocurre con muchas otras obras de Lope, sin tener en cuenta que en este caso en realidad se trata de variantes de titulación que reflejan dos momentos distintos de la redacción y dos textos, de los cuales solo uno, el segundo, es el que aquí consideraremos reflejo de la voluntad definitiva del autor. ${ }^{4}$ Esta confusión se observa también a lo largo de los textos fijados, ya que en estas ediciones no se ha prestado atención a los sucesivos momentos de intervención y al proceso de creación y revisión. Dado que en mi trabajo identifiqué como texto base la última redacción de la comedia, consecuentemente fijé el título en La encomienda bien guardada, aunque de hecho la pieza naciera como La buena guarda en su primera redacción. La cuestión del título es un buen resumen de lo ocurrido a lo largo del proceso compositivo del que nos vamos a ocupar en estas páginas: Lope redactó in primis un texto tomado del acervo popular de la leyenda de la sacristana, La buena guarda, y luego quiso transformar el desarrollo sacro del relato en profano, y trasladarlo de un contexto español a otro extranjero en La encomienda bien guardada, seguramente, como concuerdan los críticos que de ello se han ocupado, por razones de autocensura.

De los dos textos distintos que se vinieron constituyendo en el manuscrito, decidí asignar la sigla $\mathrm{O}$ a la versión definitiva, producto de una labor voluntaria de autocensura, mientras que llamé $\mathrm{O}^{1}$ a la primera redacción, La buena guarda, que aunque represente el núcleo narrativo del que se desprendió la acción, en una perspectiva global se puede considerar como el estadio primero de la creación artística, puesto que la versión representada en los corrales del siglo XVII y sucesivamente entregada a la imprenta fue la versión definitiva y censurada, La encomienda bien guardada.

La totalidad de los estudiosos que hasta hoy se han enfrentado a la difícil tarea de editar este particular manuscrito ha elegido restituir el texto en su forma

3 Hartzenbusch, Menéndez Pelayo y Díez optan efectivamente por el título La buena guarda o La encomienda bien guardada. Artigas y Crosas titulan solamente La buena guarda.

4 Paloma Cuenca Muñoz [2006], en un artículo aparecido poco después de que Stefania Capoia presentara su «tesi di Laurea» (tesis que, como es natural, Cuenca Muñoz no pudo llegar a conocer), entiende asimismo que La buena guarda y La encomienda bien guardada constituyen distintas redacciones o versiones. Si bien no acaba de decantarse por uno u otro texto, opina que la segunda versión es quizás preferible a la primera, debido a que La encomienda bien guardada «es la que sirve como texto base para la edición incluida en la Parte XV (1621), autorizada o incluso supervisada por el propio autor», y a que «la única redacción completa que tendríamos en la actualidad autógrafa de Lope de Vega es la segunda, puesto que la restitución de la primera se debe a otra mano, y sin esas restituciones es imposible recomponer el texto completo de la primera versión» (Cuenca 2006:102 y 103). Nota de los editores. 
primitiva $\left(\mathrm{O}^{1}\right.$, La buena guarda), el que supuestamente respondería a la libre voluntad del autor. Sin embargo, se pueden encontrar argumentos para tomar otra decisión editorial a favor de la versión autocensurada (O, La encomienda bien guardada), como expondré en el último apartado de este artículo. Pero desde este momento conviene dejar clara, a priori, cuál fue mi opción editorial.

A lo largo de mi trabajo tuve en cuenta principalmente dos de las mencionadas ediciones modernas. Por fortuna pude consultar el valiosísimo primer volumen de las Obras dramáticas escogidas de Eduardo Juliá Martínez, que contiene la edición crítica de La buena guarda. Este estudioso pudo trabajar en los años treinta detenidamente sobre el propio manuscrito autógrafo, entonces en posesión de los marqueses de Bondad Real. Optó por fijar como texto base la redacción originaria de la comedia, La buena guarda, y poner en aparato a pie de página las variantes de los impresos, que llevan la segunda versión censurada, La encomienda bien guardada.

En sus «observaciones preliminares» el crítico analiza la compenetración entre la vida de Lope y su obra, en la que proyectaba su personalidad y rasgos inconscientes, prestando especial atención a su faceta religiosa. De la misma manera que esos años de la vida de Lope estuvieron especialmente marcados por el fervor religioso - en 1609 ingresó en la Congregación de Esclavos del Santísimo Sacramento, en el oratorio de Caballero de Gracia, y en 1610 se adscribía al oratorio de la calle del Olivar - en La buena guarda es central la imagen de la oveja descarriada (ya presente en otras obras) y la influencia de la Biblia (sobre todo del Génesis). A continuación, Juliá Martínez define la obra como una de «las joyas del teatro religioso de Lope», subrayando el valor de la producción teatral por su «lirismo, por su desarrollo escénico y encanto popular de pasajes determinados, aunque tenga que reconocerse la debilidad episódica, achaque bastante general en Lope, quien se impresionaba hondamente por el aspecto dramático de una idea, pero con su improvisación constante se dejaba arrastrar por detalles poco vivos muchas veces» (Juliá Martínez 1934:L).

Por otro lado, tuve presente la tesis doctoral, y luego edición, de María del Carmen Artigas, Edición crítica y anotada de "La buena guarda" de Lope de Vega (University of Virginia, 1990): como se puede inferir ya desde el título, la profesora Artigas fijó el texto base en la primera redacción de la pieza, sin detenerse a estudiar ni definir las etapas redaccionales del texto presentes en el manuscrito. ${ }^{5}$ De

5 María del Carmen Artigas publicó más recientemente, en 2002, su edición en la Editorial Verbum madrileña, sin variar en lo sustancial sus elecciones textuales. Nota de los editores. 
hecho, esta edición, aunque proporciona una extensa introducción sobre el culto de la Virgen y el tema de la literatura mariana de los milagros, presenta un texto de la comedia poco fiable al mezclar los varios estadios redaccionales, sin establecer ni tener en cuenta la cronología de las diferentes intervenciones.

\section{EL AUTÓGRAFO: UN MANUSCRITO Y DOS VERSIONES O TEXTOS}

La comedia nos ha llegado en un manuscrito autógrafo y firmado, fechado el 16 de abril de 1610, que se conserva en la Biblioteca Nacional de Madrid (Ms. Vitr. 7-16). Se trata, como veremos, de un ejemplar muy particular pues contiene extensas tachaduras y anotaciones al margen de tal calado que se llegan a constituir dos versiones o textos diferentes.

El manuscrito cuenta con 60 folios, los cuales presentan dos numeraciones distintas: una foliación en el margen superior derecho que empieza en el folio 2 r, considerando 1-3 la cubierta, el folio en limpio con el ex libris de Durán y la lista de los dramatis personae (correlativa del primero al útlimo folio); y otra numeración autógrafa que empieza de nuevo al principio de cada acto (la numeración de los tres actos se inicia con una «P.» y en el primer acto se introduce un símbolo eucarístico). Los dos primeros actos cuentan con 17 folios, mientras que el tercero tiene 16.

En el centro del encabezamiento, todas las páginas que transcriben el texto de la comedia presentan la invocación religiosa abreviada típica de los manuscritos de Lope de este momento, «JM» ('Jesús, María') o «JMJ» ('Jesús, María, José). En correspondencia con los movimientos de escena suele aparecer en el margen derecho de la acotación una cruz de Malta, autógrafa. Además, también aparece una línea horizontal en relación con los cambios escénicos $(22,240,245,272$, 284, 502, 667, 815, 1267, 1391, 1685, 1930, 2138, 2347, 2393, 2529, 2646, 2764, 2822). ${ }^{6}$ En el folio 18v, más concretamente en los versos 906-919, encontramos

6 Lope corrige añadiendo un total de veintinueve versos a la redacción originaria (vv. 7-22; vv. 305-308; v. 559; vv. 1254-1257; vv. 1865-1866; vv. 2091-2092). Para calcular la correspondencia entre los versos de La buena guarda y La encomienda bien guardada, se deben realizar las siguientes operaciones sobre la base de las citas en este artículo, que remiten siempre a La encomienda bien guardada: vv. 1-6, permanecen igual; vv. 23-304, se deben restar 16 versos para averiguar el pasaje en La buena guarda; versos 309-558, se deben restar 20 versos; vv. 560-1253, se deben restar 21 versos; vv. 1258-1864, se deben restar 25 versos; vv. 1867-2090, se deben restar 27 versos; vv. 20932960, se deben restar 29 versos. Las ediciones de Hartzenbusch (p. 340a) y Menéndez Pelayo (p. 351a) incorporan por error un verso perteneciente a la segunda versión (el 2301 de La encomienda 
un detalle que nos llama la atención. En esta escena, el personaje de doña Clara está leyendo una carta, y para distinguir los distintos registros de la lectura y del discurso oral, Lope emplea el recurso gráfico de subrayar los fragmentos de carta leída. Para una descripción completa del manuscrito, remito al catálogo de Presotto [2000:221-227].

En la introducción al trabajo arriba citado, Presotto pone de relieve el cuidado con que Lope compuso sus manuscritos, que sin duda estaban destinados a la venta y a la representación, como se deduce por la presencia de las licencias finales (en nuestro caso, Madrid, 27.IV.1610-16.VI.1610, T. Gracián Dantisco Tejada; Sevilla, 29.V.1611, B. de Gálvez, M. de Almirante; Madrid, 3.XI.1614, L. Treviño, A. de Illescas). En ningún caso se trata de borradores (cuya existencia está todavía por demostrar), sino de versiones definitivas y cuidadas cuyo molde de redacción permanece esencialmente invariable a lo largo de los años (Presotto 2000).

Las consideraciones hechas por Presotto sobre el proceso compositivo de las comedias encuentran relativa excepción en el caso de este manuscrito autógrafo, que, además de las intervenciones autógrafas in itinere, presenta numerosas correcciones de autor pertenecientes a una fase sucesiva a la primera redacción: se trata de un importante número de versos tachados y corregidos por Lope, con tinta distinta de la del texto primigenio, donde parece evidente la intención de cambiar esencialmente el lugar de la acción y el estado de su personaje principal. ${ }^{8}$ Estas intervenciones autógrafas posteriores eliminan el nombre de la ciudad en que se desarrolla la comedia, Ciudad Rodrigo, y por lo general, toda referencia a sitios españoles. La iglesia y el convento se convierten en un oratorio para señoritas casaderas, y

bien guardada), pero sin dejar de transcribir el verso correspondiente de La buena guarda, que es el texto que editan en ambos casos. El resultado es que estas ediciones incorporan un verso de más, que queda suelto y sin rima en un pasaje formado por redondillas. El error se ha transmitido a la edición de ARTElope, que sigue el texto de Menéndez Pelayo, razón por la cual el cómputo global de versos de dicha edición es de 2932 y no de 2931, al contrario de lo que se esperaría teniendo en cuenta que el texto de La encomienda bien guardada, que cuenta con 2960 versos según el recuento de Capoia, añade un total de 29 versos al de La buena guarda. Este error, que consiste en la incorporación del verso «No te vayas, desdén mío» (el 2273 según la edición de La buena guarda de ARTELOPE), propicia además que la lógica correspondencia de versos entre La buena guarda y La encomienda bien guarda se vea alterada a partir de ese pasaje. Nota de los editores.

7 Sobre las distintas marcas de segmentación resulta ahora imprescindible el estudio de Crivellari [2013]. Para las características de los manuscritos de Lope, véase asimismo Cuenca Muñoz [1999]. Nota de los editores.

8 Algunos de los casos que se presentan a continuación han sido analizados también por Juliá Martínez en su edición [1934] así como en su estudio por Paloma Cuenca [2006]. 
a la protagonista, doña Clara, se le quita el título y la condición de abadesa y esposa de Cristo. De ahí que las numerosas y extensas tachaduras lleguen a constituir, a mi juicio, otro texto, veintinueve versos más largo $(\mathrm{O})$, producto de una relectura sucesiva de la comedia, que incorpora la primera redacción $\left(\mathrm{O}^{1}\right)$ y la transforma en un relato más laico y, en consecuencia, más aceptable por parte de los censores y las mentes más pacatas de la época.

\section{ANÁLISIS Y CLASIFICACIÓN DE VARIANTES}

A continuación se ofrecen las variantes de las dos versiones enfrentadas, con la numeración correspondiente al texto de La encomienda bien guardada. El caso quizás más significativo se encuentra precisamente al comienzo del acto primero, donde Lope, tachando los seis versos iniciales de la versión originaria, los quiere sustituir por veintidós versos añadidos en el vuelto del folio anterior, en cuyo recto figuraba el reparto: ${ }^{9}$

$\mathrm{O}^{1}$

[f.4 $\quad$ Entren dos damas con mantos y con sus escuderos. LEONARDA

Tarde pienso q venimos. DoÑa LUISA

Sin missa nos quedaremos. Escudero

La yntençión ofrezeremos. LEONARDA

Culpa de tardar tubimos, aunq yo, por aguardaros, la tengo mucho mayor.

\section{$\mathrm{O}$}

Dos damas con mantos y sus escuderos.

LEONARDA

Tarde pienso q venimos. DoÑa LUISA

Sin missa nos quedaremos. EsCUDERo

La yntençión ofrezeremos. LEONARDA

Notable culpa tubimos

en venir a este oratorio

destas señoras donzellas.

DoÑa LUISA

Tienes deboçión con ellas. Escudero

Pues no era claro y notorio q no hauía de haber missa pues no es yglesia.

9 Puede consultarse una reproducción digital del manuscrito autógrafo en la sección «Biblioteca digital hispánica» de la página web de la Biblioteca Nacional. 
LEONARDA

Otras vezes

$<$-dos o tres suelen deçir

$\backslash \backslash$ la has perdido // bien

merezes>

$<$-EscUD.

Una les he visto ...gr...

$\backslash \backslash$ perder //por ser remisa>

<-y q la pierdas merezes.>

DoÑa LUISA

En este recogimiento

q las donzellas anpara,

Leonarda, está doña Clara.

LEONARDA

¡Qué hermosa!

DoÑa LUISA

¡Qué entendimiento!

LEONARDA

¿No se acaba de cassar?

DoÑa LUISA

Pienso q da en santa agora.

Escudero

Es la más bella señora

q tiene todo el lugar;

mas ya vienen a buscaros

Amadís y Galaor.

Parece evidente la voluntad del poeta de cambiar el lugar y el contexto en que se desarrolla la acción: aunque los seis versos tachados no llevan todavía ninguna referencia a la versión originaria, en los veintidós versos del nuevo comienzo Lope quiere plantear enseguida la nueva localización de la comedia que nos sitúa en un oratorio o recogimiento que gobierna doña Clara, cuya hermosura no es menor que su virtuosa actitud.

En los lugares presentados más abajo puedo identificar con cierta seguridad por razones semánticas, y después del análisis de la tinta realizado directamente sobre el manuscrito autógrafo, que las correcciones pertenecen a una relectura 
sucesiva y censuradora de la leyenda mariana (la evolución de $\mathrm{O}^{1}$ a $\mathrm{O}$ ). ${ }^{10}$ Subrayo las palabras tachadas y corregidas en el papel. He reunido las correcciones de autor en dos grupos, clasificadas por las causas que las produjeron: en efecto, en todo cambio se identifica esencialmente la voluntad de quitar el trasfondo religioso (al que se alude con lugares sacros, con hábitos, con nombres o saludos) o de mudar la acción de una ciudad (quizás famosa) y por lo general de España al extranjero. No es necesario decir que cuando el cambio acontece a final de verso y afecta a la rima, el autor tuvo que intervenir también en los versos anteriores o siguientes.

Ofrezco a continuación los versos en que Lope quiso eliminar las referencias toponímicas más específicamente españolas para plantear la historia en un contexto indefinido entre Italia, España y Francia.

$$
\mathrm{O}^{1}
$$

de camino como digo

no hauía en ciudad Rodrigo

bamos a la gran Toledo

q en nonbrándola no puedo

pues no bamos a Toledo

$\mathrm{y}$ si buscas gente fea

pasémonos a Guinea

viuirás perdido el miedo

pardiéz vamos a Seuilla

FELIS

o q famosa çiudad

CARRIZO

y de mayor libertad

q las q tiene Castilla

\section{$\mathrm{O}$}

y de camino en verdad

que no hauía en la ciudad

(vv. 66-67)

bamos a Nápoles bella

q para regalo en ella

(vv. 1631-1632)

digo q no bamos ya

y si buscas gente fea

pasémonos a Guinea

no abrá çelos allá

(vv. 1637-1640)

vamos a Françia o París

FELIS

o q famosa ciudad

CARrizo

y de mayor libertad

q todas las q deçís

(vv. 1646-1649)

10 Aunque no entre en el detalle del análisis que aquí se plantea de las variantes, resulta de todo punto admirable y de recomendable lectura del artículo de P. Cuenca [2006] con su identificación de las distintas manos que intervienen, y momentos en que intervienen, en el manuscrito. Nota de los editores. 
de nabes y de estrangeros

aunq en toda España abrá

a Valençia puedes yr

o podéys por Vinarrós passar a Ytalia o por ella

DoÑa Clara

$\underline{\text { todo el amor lo atropella }}$ muramos juntos los dos vamos a qualquier lugar

FeLIS

haçia Toledo camino o Valençia si ymagina

Clara q la han de buscar

pienso dar la buelta a Ytalia

ven Carrizo

Carrizo

adónde

FELIS de tratos y de estrangeros

(v. 1652)

aunq en todo el mundo abrá

(v. 1656)

a Genobas puedes yr

(v. 1658)

q por ella Vinarrós

a España podéys passar

DoÑa ClaRa

amor no suele dudar

muramos juntos los dos

vamos a qualquiera parte

FELIS

donde quisieres camino

si tu recelo ymagina

g tu padre ha de buscarte

(vv. 1666-1673)

pienso dar la buelta a Françia

(v. 1905)

ven Carrizo

CARRIZO

Adónde

FELIS

a Françia

(v. 1924) 
Mil vezes oy en Castilla q en el Col de Balager hauía bien q temer ya porq es del mar la orilla y moros de Árgel piratas entre calas y recodos donde después salen todos tienen ocultas fragatas ya porq en él por pasiones nunca falten vandoleros

en España

CARrizo

triste voy

q de España a Ytalia fuimos

nos lleba a çiudad Rodrigo y yo pienso q al castigo

al fin bolbimos a España como ya desconozidos en rostros barba y vestidos si el tiempo no nos engaña ya salimos de la mar y entramos en Barçelona donde hallamos persona

q nos pudiesse juzgar menos q por estrangeros lo mismo será en Madrid Toledo y Valladolid
Mil vezes oy decir q en esta orilla del mar hauía bien q pensar porq aquí suelen surgir los moros de Árgel piratas q entre calas y recodos de quien después salen todos tienen ocultas fragatas y q çiuiles pasiones tanbién causan vandoleros

(vv. 2001-2010) en Ytalia

CARRIzo

triste voy (v. 2023)

q de Ytalia a Françia fuimos

nos lleba a la patria agora de aquella pobre señora

(vv. 2034-2035)

al fin bolbimos señor como ya desconozidos en rostros barba y vestidos asegurando el temor ya salimos de la mar y entramos en nuestra tierra $\underline{\text { FELIS }}$

al cabo de tanta guerra seguro puedo pasar de que seré conocido bien sé que seguros vamos que todos los que tratamos y nos han visto y oydo nos tienen por estrangeros

(vv. 2085-2097) 
la ribera del Tajo en ellas viben

las márgenes del Tajo y dase en ellas

$\underline{\text { de los montes de Toledo }}$

q te ha causado tal miedo

de tantas flores el Tajo

Cosme

está en tu aposento

DoÑa ClaRA

Sí

Cosme

pues yo buelbo luego aquí porq buelo y sé el atajo

Labareme en el Tajo

en la sagra de Toledo.

q vi en el Tormes la tarde

en las orillas del Tajo

desde aquí a çiudad Rodrigo la ribera del río en ellas viben

(v. 2184)

las márgenes del río y dase en ellas

(v. 2199)

desta fragosa arboleda

q tal miedo darte pueda

(vv. 2282-2283)

de tantas flores el río

Cosme

está en tu aposento

DoÑa Clara

Sí

\section{Cosme}

pues yo buelbo luego aquí

no te bayas desdén mío

(vv. 2298-2301)

Labareme en el río

(v. 2316)

D. Clara

Vençí vitoriosa quedo

(v. 2387)

q vi en mi patria la tarde

(v. 2454)

orillas de aqueste río

(v. 2466)

desde aquí a la patria mía

(v. 2524) 
y no ay en çiudad Rodrigo

y sola en çiudad Rodrigo

y otra cassada en Salamanca

CARRIZO

çielos

en Madrid lo está

la que llebaste a Toledo

y apenas tienes amigo

(v. 2610)

en la çiudad sin testigo

(v. 2676)

y otra cassada en Nápoles

CARRIZO

ay çielos

(v. 2803)

Doña Clara

adónde

PorTera

en Milán lo está

(v. 2876)

la que llebaste a Milán

(v. 2911)

El segundo grupo de intervenciones lopescas está motivado por la voluntad de eliminar el trasfondo religioso de la comedia y convertirlo en un relato más profano. Por ejemplo, doña Clara ya no era la esposa de Cristo y la abadesa de un convento, sino de la directora de una casa para doncellas. Cada elemento que se relaciona con este contexto sacro es sustituido en favor de la creación de un relato laico en que la traición ya no lleva connotaciones de pecado contra Dios y la religión. Se trata de los versos que transcribo a continuación:

$\mathrm{O}^{1}$

q este hará grande misterio de qualquier cosa que ynpida

Don LUIS

no he de venir en mi vida

a missa a este monasterio

destas monjas sacristán

\section{$\mathrm{O}$}

q este hará grande aspamiento de qualquier cosa que ynpida

Don LuIs no he de venir en mi vida a missa al recogimiento (v. 217-220) desta casa sacristán (v. 286) 
para q se heche de ver

en toda Ciudad Rodrigo

$\underline{\text { CARRIZO }}$

eso digo

y es muy principal muger

ay de mí q no me he visto jamás en dolor tan fiero y más quando considero q es Clara esposa de Cristo pues qué yntento, qué pretendo con ofender tal esposo

Deo gratias o qué mal digo q no es dar graçias a Dios sino ofenderle mas vos templad Señor el castigo Deo gratias a mi señora la abadesa soror Juana a es abadesa

para q se heche de ver

q en este recogimiento

de donzellas cuyo intento

es casarse, puede saber quién tenga tanbién cuidado puesto q es sólo oratorio

CARrizo

esso es mui claro y notorio

y q ha de ser celebrado

(vv. 301-308)

ay de mí en tanto mal

ya ningún remedio espero

y más quando considero

q es Clara tan principal pues qué yntento qué pretendo si espera tan rico esposo

(vv. 349-354)

a de allá dentro a quien digo tenblando llego por Dios ay pensamiento por vos me espera tan gran castigo está cerca mi señora doña Clara diga hermana (v. 365-370)

Entre doña Clara, monja en el ábito que Entre doña Clara dama gallarda para cassarse parezca más a propósito más a propósito vestida en recogimiento

$$
\text { (v. 372Acot) }
$$

por santa en tan verdes años madre, aunque en tan verdes años deste convento os han hecho de aqueste recogimiento abadesa 
Doña Clara

no sospecho

q en eso estén vuestros daños

q si es falta que le hacéys

al convento oy me prefiero

FeLIS

no puede ser q es cassada

q deso tengo anegada

el alma entre fuego y yelo

DoÑa ClaRA

cassada

FELIS

señora sí

y es tan alto su marido

q tienblo en verle ofendido

de mi pensamiento aquí

tiene notable poder

mas tanbién es piadoso

os haga amar religiosa

FELIS

religiosa y tan hermosa

q por sus ojos me abraso

$\underline{\text { FELIS }}$

$\underline{\text { no sea con vos malquisto }}$

DoÑa Clara

si el demonio os tienta oy

acordaos Felis q soy

esposa de Jesucristo
Doña Clara

yo no siento

q en eso estén vuestros daños

q si es falta que le hacéys

a esta casa oy me prefiero

(vv. 417-422)

FELIS

no puede ser q es mui alta

y el mérito que me falta

me pone entre fuego y yelo

DoÑa ClaRA

mui alta

FELIS

señora sí

y es tan alta que he pensado

q aumento en haberla amado

la humildad con que naçí

dizen q espera tener

cierto esposo poderoso

(vv. 438-446)

os haga amar aquí en casa

FELIS

la hermosura que me abrasa

está de mi sólo un paso

(vv. 462-464)

mirad q aunq me habéys visto con yntençión de casarme pienso mui presto enplearme

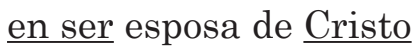

(vv. 485-488) 
después q Clara religión profesa

casi por mi heredera porq creo

por vivir religiosa y de tal suerte q por su santidad en verdes años

su hermana y nuestra abadesa

q Dios guarde acá le enbía esta fruta y a fee mía

q de no poder me pesa

probarla porq oy ayuno

ELENA

q santidad

Don PedRo

es exenplo

desta çiudad

ELENA

aquel tenplo

no produce árbol ninguno

que de tal fruto no sea

nunca mi esposo permita

q oy la señora abadesa

q de enbialle no cesa

entraré en la portería

q está hablando con fray Juan después q Clara recogida vibe porq lo q es casarse pongo en duda casi por mi heredera porq creo

(vv. 558-561)

por no quere casarse aunq la ruegas pues por su santidad en verdes años

(vv. 592-593)

su hermana y nuestra señora

q Dios guarde acá le enbía esta fruta y a fee mía

q de no poder agora probarla porq oy ayuno

Elena

q santidad

Don Pedro

$$
\text { es notoria }
$$

ELENA

a gloria

no tener defeto alguno

pero quien ay que tal sea

(vv. 616-624)

ay nunca el çielo permita

(v. 770)

q oy su hermana doña Clara

q de enbialle no para

(vv. 870-871)

ayudaré su porfía

pues a casamiento van

(vv. 884-885) 
Doña Clara

Deo graçias

CARRIZO

por sienpre

DoÑa Clara

$\underline{\text { dio }}$

busca un vestido seglar

un rico seglar vestido

voy a perdirme en tanto bituperio quedéys en guarda desto monasterio

y vos esposo mío aunq os ofendo y pierdo el nonbre aquí de va esposa guardad estas obejas

con aqsta miserable

que a su esposo vinerable

ha hecho tan vil trayçión

maitines tocan yo quiero

q después de Dios María

fue sienpre la buena guarda
DoÑa Clara

hermano Carrizo dio

(v. 896)

busca en q pueda salir

(v. 994)

para el camino un vestido

(v. 1073)

voy a perdirme porq amor me abrasa quedéys en guarda desta humilde casa

(vv. 1170-1171)

estas donzellas dexo y vos ofendo casaldas vos con mano generosa guardaldas Virgen santa

(vv. 1182-1184)

con aqsta cuyo intento pudiera con casamiento remediar su perdiçión <-por> q estaua aquí recogida con donzellas por cassar

q hasta verse remediar pasauan honesta vida ello es ya tarde yo quiero (vv. 1253-1260)

q después de Dios María fue sienpre la mexor guarda

(vv. 1266-1267) 
el sacristán desta cassa

honbre que de santo passa

o trae el nonbre postizo

mi señora la abadesa

q como sabe professa

tanta virtud y humildad

le suplica q se llegue

un rato a la portería

Don Carlos

a la noche busca el día

La portera

el coro y claustro de afuera

la abadessa la primera

q como el primero esposo

me dió Felis estas armas

y nunca el amor primero

de todo punto se acaba

de Cristo sobre mi cuello

tu esposo del adulterio

$\mathrm{y} \sin$ mi querido esposo sacristán del oratorio de las donzellas notorio

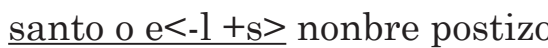

(vv. 1333-1335)

mi señora doña Clara

q el recigimiento anpara

desta famosa çiudad

le suplica q se llegue

q quiere hablarle en su sala

Don Carlos

q pena a mi pena yguala

(vv. 1357-1362)

Una donzella entre

(v. 1782Acot)

esta cassa las donzellas

y su gouierno con ellas

(vv. 1820)

no me pensaua casar

aunq recoxida estaua

para casarme, que hize

boto y me puse estas armas

y como el primero amor

o nunca o tarde se acaba

(vv. 1861-1866)

del çielo sobre mi cuello

(v. 1875)

tu padre de la traiçión

(v. 1943)

y sin el mexor esposo

(v. 1955) 
el esposo q ofendía

yo vibo con mi esposo regalado en otro matrimonio diferente

Don Pedro

dichosa quien escoje tal estado

en la portería entré

ÁNGEL

q es esto

Don CARLOS

en el locutorio

acude presto acude sóror Clara

q sóror Madalena en este punto

entró por él y sin moxarse el hábito

assió de un brazo a sóror Madalena

gente ay en la portería

quien es abadessa agora

deste santo monasterio

porq la quisiera hablar

ay Dios quién ha de contar

tal deshonra y vituperio

DON CARLOS

la q es abadessa aquí

es doña Clara de Lara la nobleza q ofendía

(v. 2078)

yo buscaré un esposo regalado

en otro matrimonio diferente

Don Pedro

dichosa si escogieres tal estado

(vv. 2542-2544)

al recogimiento entré

(v. 2565)

ÁNGEL

q es esto

Don Carlos

en el oratorio

(v. 2596)

acude presto acude hermosa Clara

q doña Madalena en este punto

(vv. 2640-2641)

entró por él y sin moxarse nada assió de un brazo a doña Madalena

(vv. 2663-2664)

Aquí ay gente, ay casa mía

(v. 2681)

quien es quien gobierna aora aqste recogimiento

de damas para casar

porq la quisiera hablar

ay Dios q venganza siento

Don CARLOS

la q oy gobierna aquí

es doña Clara de Lara

(vv. 2696-2702) 
viue en este santo tenplo

dando a todo el mundo exenplo

soys señora la abadesa

q tengo mucho que hablaros

y solamente en miraros

pareze q el miedo çessa

Clara en tu conbento estás

entra y en tu çelda propia

el hábito q dexaste

quando a tu esposo negaste

con tu boto haçaña ynpropia

toma del mismo lugar

porq te buelba tu esposo

como de Dios reçiue

FELIS

este es el tenplo

tienen las monjas llega y ábla...

baya a la de la yglessia

CARRIZO

diga hermano

quién es el sacristán q agora sirbe este conuento

Fingido no se ha querido cassar

la admira todo el lugar

(vv. 2710-2711)

soys la q gobierna aquí

q tengo mucho que hablaros

y solamente en miraros

todo mi temor perdí

(vv. 2725-2728)

Clara en tu casa estás

entra q en esse aposento

hallarás q to dexaste

quando tu honor oluidaste

y el deste recoximiento

buelbe a ocupar tu lugar

(vv. 2736-2741)

y buelbe a mexor esposo

(v. 2754)

como de Dios reçiue

FELIS

esta es la casa

(v. 2769)

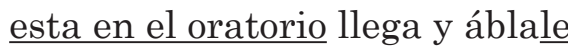

(v. 3783)

baya a la de los pobres

CARRIZO

diga hermano

quién es el sacristán q agora sirbe este oratorio

FINGIDO

yo no me conoze

(vv. 2786-2788) 
muerto? agora le vi con la abadesa

FELIS

y quién es la abadesa

Fingido

doña Clara

procuremos hablar a la abadessa

Éntrense y salgan doña Clara ya en su primero hábito y don Pedro su padre

La portera y el platero

PorTera

agora lo puede hazer

firme vuestra caridad

esta çedula a Lanberto

DoÑa Clara

cómo

PorTera

q viue es lo çierto

Clara en otra claridad

PorTERA

la firma porque no espere

pues yo haré mi dulçe esposo

por estarlo ... en vos con ansias

tan amorosas y dulçes

q allá se me quede el alma muerto? agora le vi con nro dueño

FELIS

y quién gouierna agora

FINGIDO

doña Clara

(vv. 2811-2812)

procuremos hablar a esta señora

(v. 2820)

Éntrense y salgan doña Clara ya en su primero vestido y don Pedro su padre

$$
\text { (v. 2822Acot) }
$$

Una criada y el platero

(v. 2852Acot)

$\underline{\text { CRIADA }}$

agora lo puede hazer

vuesa merzed firme aquí

esta çedula a Lanberto

DoÑa Clara

cómo

Portera

$q$ viue es lo çierto

Clara mui lexos de aquí

(vv. 2854-2858)

$\underline{\text { CRIADA }}$

la firma porque no espere

(v. 2861)

pues casarme ya no es justo

yo cunpliré la palabra

q he dado al mexor esposo

y en dote le ofrezco el alma

(vv. 2899-2902) 


\author{
en tu hábito en tu honor \\ en tu virtud y en tu cassa \\ Doña Clara \\ quando salí del conuento
}

\author{
en tu centro en tu honor \\ en tu virtud y en tu cassa \\ DoÑa Clara \\ quando salí desta puerta
}

(vv. 2923-2925)

\section{VARIANTES DE TITULACIÓN}

Finalmente hay dos casos en que el autor no interviene para corregir el texto originario por las razones dichas - aunque al analizar la tinta parece que sean intervenciones contemporáneas a la relectura de la comedia-, sino para realizar el cambio de título. Tanto en los cierres del primer y segundo acto (f.20r, f.40r), como en las portadas del segundo y del tercero (f.22r, f.42r) se apunta el título de La buena guarda, mientras que la portada principal lleva la variante de La encomienda bien guardada, y consecuentemente los versos finales del segundo y tercer acto están modificados como sigue:

$\mathrm{O}^{1}$

buena guarda buena guarda

aquí la comedia acaba como verdadera historia senado la buena guarda
$\mathrm{O}$

pues conozes q son tantas

(v. 2000)

aquí para exenplo acaba como verdadera historia la encomienda bien guardada

(vv. 2958-2960)

La locución de «buena guarda» aparece en los versos 1195, 1778, 2646, 2760, 2930 y queda invariada en la reescritura de Lope; en cambio está tachada y corregida en el verso 1267. Por lo que concierne a las licencias, como se puede leer en la transcripción del manuscrito hecha por Presotto, las de 1610 y 1611 aprueban la comedia como La encomienda bien guardada, y en cambio la licencia de 1614 se refiere al título originario de La buena guarda. ${ }^{11}$

11 ¿Cabe la posibilidad de que se pusiera en algún momento en escena La buena guarda, superados los escrúpulos? De hecho, una de las manos que interviene en el manuscrito para restaurar 
Estos datos me llevan a apuntar por un lado que el cambio se produjo en un momento sucesivo y próximo a la primera redacción completa de la comedia y, por otro, que este momento debe de situarse o en la fecha en la que el mismo Lope afirma acabar la obra (16 de abril de 1610), o entre esta fecha de conclusión y la de la primera licencia (27 de abril de 1610). ${ }^{12}$ Merece especial cuidado señalar otra característica del autógrafo: la presencia de grafías distintas de las de Lope que intervienen en el manuscrito. ${ }^{13}$

\section{LA INTERVENCIÓN DEL AUTOR DE COMEDIAS}

Por un lado se puede identificar, como era usual, la intervención del autor de comedias al que se vendió el manuscrito: se tacha el verso 536, probablemente por exigencias escénicas (en el tablado resulta pesada la figura retórica de la enumeración); de la misma forma está tachado el verso 559, llamativamente añadido en la sistemática revisión que el autor mismo hizo de su comedia, e innecesario para el desarrollo de la acción, así como el verso 773, que se repite en el folio 16r; los versos 1140-1155 (dos octavas) están enjaulados por dos líneas horizontales y una vertical para cortar la larga oración que doña Clara hace a la Virgen antes de salir del convento con su amante; se tachan con dos líneas verticales los versos 2139-2242, en que se desarrolla la escena, paralela e independiente de la historia principal, entre los villanos Liseno y su hijo Cosme, cuya presencia no añade ni quita nada a la acción y por eso el autor de comedias la puede excluir de la representación (según

lecciones previamente tachadas es, según la paleógrafa Cuenca Muñoz [2006:102], del propio siglo XVII. Así se explicaría que esas censuras llevaran el título de La buena guarda. Otra posibilidad es que la presencia de ambos títulos en el mismo manuscrito indujera a confusión: de hecho, en los impresos del xvir, aunque el texto reproducido es el censurado de La encomienda bien guardada, lleva el título de La buena guarda. Nota de los editores.

12 Respecto a esta cuestión, Paloma Cuenca [2006:100] afirma, sin embargo, lo siguiente: «No sabemos tampoco cuándo lleva a cabo Lope su revisión del texto de la misma para la segunda versión, a lo profano. Quizá fuera inmediatamente después de haberla redactado o bien, en un plazo más largo, durante los años que van desde la fecha del autógrafo (1610) a la edición de la comedia (1621), basada en la versión definitiva. Es posible que Lope, ordenado sacerdote un año después de haber firmado la primera redacción del autógrafo, hubiera tomado la decisión él mismo de atenuar el contenido religioso del primitivo argumento y alterar la ubicación geográfica de la leyenda». También aborda esta cuestión el pasaje de Juliá Martínez [1934:XLIX-L], «La intervención de un lector restaurador». Nota de los editores.

13 Para la mejor comprensión de este aspecto del manuscrito, las distintas manos que intervienen en distintas fases, véase el excelente análisis paleográfico de Cuenca [2006]. Nota de los editores. 
Juliá Martínez 1934:65, la «escena y el monólogo de Cosme se encuentran tachados en el manuscrito, como tachaban con una raya los cómicos»); de la misma forma se tachan, con «la raya que parece indicar supresión hecha por los cómicos» (Juliá Martínez 1934:202), los versos 2344-2375, 2376-2393 y 2410-2441, quizá por no ser esenciales para el desarrollo de la comedia.

Además, quisiera señalar también seis lugares en los que se corrige el texto del poeta: después de un detenido análisis de la forma de las tachaduras, de la tinta empleada y del tipo de grafía (de acuerdo con la lectura de Juliá Martínez), cabe concluir que se trata de notas apuntadas por los cómicos. En detalle, en el verso 285 , interlineado entre los versos tachados por el mismo Lope, se lee «en este conuento amigo» en rima con el verso anterior, tachado, que citaba a Ciudad Rodrigo (quizás se equivoca al leer lo que está bajo la tachadura); en el verso 577 se tacha la palabra "claustro» para enmendarla arriba con "patio»; asimismo en el verso 1200 se corrige «hábitos» por «ropas tú»; en el verso 1361 se lee sobre el verso tachado en la revisión de la comedia «un», quizás escrito en el intento de leer lo que se encuentra bajo la tachadura; en el verso 1750 se tacha "a Salamanca» y se la sustituye primero por «algún París» (tachado) y luego por «a Bolonia»; en el verso 1883 se corrige «tres» con «dos». Sin embargo, todas estas intervenciones parecen encaminadas a dar coherencia a la nueva versión que Lope mismo quiso realizar de su texto: se mantiene la tendencia a tachar todo trasfondo religioso y los lugares de referencia a España. Puede ser que, como a Lope se le escapó corregir estas palabras a lo largo de la revisión de su obra, tuvieran que enmendarlas los actores que iban a representar la pieza en el tablado, completando y perfeccionando la tarea de revisión emprendida por el poeta.

Asimismo, se encuentran a lo largo del manuscrito unas intervenciones ajenas a Lope que se remiten siempre a la mano del autor de comedias, porque siguen con el objetivo de la coherencia escénica: de hecho, atañen a las didascalias y acotaciones que faltan. Se presentan en 373Per (Cla.), 665Per (CARr.), 1931Per (Hues.), 2127Per - 2129Per (<-3 + 2), 2327Per (CLA.), 2785Per (Fin.), 2852Acot (y la portera).

Finalmente, señalo que en el verso 1920 se subraya el momento escénico con «ojo» en el margen izquierdo. Esta indicación suele ser típica del autor de comedias, cuando los versos que va leyendo llevan alguna referencia semántica o solución escénica que no se ajusta perfectamente a las exigencias de la representación: en este caso no se consigue identificar la causa, sino que probablemente se subraya el 
momento narrativo en que se plantean las condiciones para el epílogo de la acción, en este caso el abandono de la monja por parte del amante, que produce sucesivamente su arrepentimiento y el regreso al oratorio y a su carga. A lo mejor al cómico no le gustaba la idea de dejar a la amada encargando al huésped que le entregue una carta mientras Felis y Carrizo se marchan.

\section{LA INTERVENCIÓN DE UN LECTOR RESTAURADOR}

Por otro lado, cuestión muy diferente e inusual es la presencia de una tercera grafía que interviene al lado de las tachaduras y correcciones introducidas por Lope a lo largo de la relectura de su obra. Se escriben nuevamente los versos que el poeta quiso borrar de su versión originaria: en efecto, parece identificarse la tentativa de establecer la esencia primigenia de la leyenda mariana. La transcripción y restauración de los fragmentos tachados es sistemática: vv. 1-6, 217, 220, 349-350, 352, 354 (se equivoca al leer «en ofender» en lugar de «como ofendo»), 365-370 (enmienda lo que escribe en el verso 367), 417-419, 439, 442-446 (se equivoca en el verso 443 escribiendo «tiemblo auerle ofendido» en lugar de "tiemblo en verle ofendido»), 463-464, 485-487, 558, 592, 1182 (ya no se consigue leer porque la tinta se ha desteñido), 1358-1359, 1362, 2542, 2698, 2700, 2710, 2738-2740, 2783 (se equivoca al escribir «aquestas monjas» en lugar de «tienen las monjas»), 2788, 2899-2902, 2925. De la enumeración hecha se infiere que no todos los lugares que llevan doble texto (ya listados arriba) están reconstruidos por esta tercera mano: en la mayoría de los casos creo que se puede justificar la falta porque la forma de borrar de vez en cuando no es tan marcada, permitiendo leer lo que leía la versión originaria o, al contrario, porque la tachadura no deja rastro de las letras.

Resumiendo, hemos indicado que el autógrafo presenta enmiendas que son de dos clases: unas que revelan vacilaciones del poeta y se hicieron a vuela pluma en el momento mismo de la improvisación, y otras que modifican el texto central sistemáticamente. Como tales rectificaciones destruyen las alusiones geográficas y el carácter monástico de la protagonista, se ha supuesto que se debieron a la censura. Concuerdo con las conclusiones expuestas por Juliá Martínez que cito a continuación:

Tengo para mí que [las enmiendas] surgieron poco después de terminar la obra, y por propio impulso del autor, si bien puede aceptarse que existió alguna sugestión 
amistosa; y tal creo, porque en las censuras no se apunta que se necesite acometer modificación alguna; tampoco hay retraso en la concesión de las licencias; muchos versos tachados se repiten interlineados o al margen sin variación de ningún género, y finalmente estaba reciente el caso de La conversión de San Agustín, prohibida por la Inquisición, y es natural que Lope, después de su conducta anterior, pusiera todos los medios para que no se repitiese el caso. El manuscrito tiene además signos que revelan que fue usado para la representación: de haber sido censurado con notas desfavorables no se habría permitido su manejo público con tanta facilidad (Juliá Martínez 1934:XLIX-L).

LOS IMPRESOS

La comedia fue impresa con el título de La buena guarda en la Decimaquinta Parte de las comedias de Lope de Vega Carpio, Procurador fiscal de la Cámara Apostólica, y familiar del Santo Oficio de la Inquisición. Dirigidas a diversas personas. Maria Grazia Profeti [1988:194-195] identificó dos ediciones:

A: En Madrid. Por la Viuda de Alonso Martín. A costa de Alonso Pérez, mercader de libros, año 1621. Se ha visionado el ejemplar en microfilm conservado en la Biblioteca Nacional de Madrid, con signatura R- 13866.

B: En Madrid. Por Fernando Correa de Montenegro. A costa de Alonso Pérez, mercader de libros, año 1621. Se ha visionado el ejemplar en microfilm conservado en la Biblioteca Nacional de Madrid, con signatura R- 25122.

Ambas ediciones llevan el texto de La encomienda bien guardada, o sea, la versión autocensurada de la comedia: en consecuencia, las variantes que puse en aparato a pie de página de mi edición crítica consisten, en la mayoría de los casos, en errores inconscientes causados por una lectio facilior o trivialización del copista (Blecua 1990:25) o, en otros casos, atañen principalmente al paratexto, es decir a las acotaciones, producto del cambio de destino que tuvo un texto escrito para el teatro, que ahora iba a ser publicado para la lectura individual. ${ }^{14}$ De ahí que si en el manuscrito encontramos las indicaciones escénicas en subjuntivo, sistemáticamente en los impresos encontramos el verbo en indicativo.

$14 \mathrm{Al}$ respecto, véase Profeti [1996b]. 
Quiero destacar unas variantes que quizás me permiten establecer una transmisión textual directa entre el manuscrito y la Parte: en los versos 2184 y 2199 los impresos concuerdan en llevar la primera lección que presenta el autógrafo, donde Lope quiso borrar el nombre del «Tajo» por la exigencia de quitar toda referencia a lugares españoles, y sustituirlo por un más genérico «río». La enmienda está sobrescrita en el interior del verso y puede ser que el copista al leer el pasaje no se diera cuenta de cuál era la lección definitiva o que no prestara mucha atención al sentido general puesto que en las demás enmiendas de la escena siguiente (vv. 2298, 2316) transcribe la versión censurada.

Otro caso muy interesante se encuentra en el v. 285, donde los impresos omiten la indicación de personaje "CARR.», escrita en el manuscrito con grafía diferente de la de Lope. Puede suponerse que el copista, al darse cuenta de que se trataba de una intervención ajena a la voluntad del autor, quiso mantenerse fiel al texto de Lope, haciendo caso omiso de la corrección. Asimismo, se podría pensar que esa corrección manuscrita fue posterior a la impresión de la Parte.

Finalmente, me parece muy significativa la variante que se encuentra en el verso 502Acot, que el manuscrito transcribe como Váyase y salgan don Pedro y Ricardo, viejos. En esta ocasión tenemos que el testimonio $A$ cae en un error por atracción, asimilando los dos verbos al plural, puesto que la acotación lleva dos sujetos (Vanse y salen), mientras que $B$ respeta el diferente número de persona y la coherencia escénica (Vase y salen). Además, en el verso 510, A cae en un error por sustitución: dado que el verso anterior acaba en "generosa», el copista sustituye el adjetivo «virtuoso» por "generoso»; pero esto no ocurre en la edición $B$. Por otra parte, en el verso 645 el manuscrito presenta un error en la acotación: Lope se equivocó al atribuir ambas intervenciones al mismo personaje. En el cotejo con los impresos $B$ copia el error autógrafo, mientras que $A$ intervino corrigiendo el segundo personaje.

De estos pocos datos se puede inferir la hipótesis de que es posible que $A$ dependa de $B$, pero no al revés: $B$ no puede depender de $A$ porque no es posible que en el proceso de copia se hayan producido tales enmiendas.

Finalmente, del cotejo de los impresos he identificado el mismo número de erratas en ambas ediciones: son evidentemente errores que se han producido en el proceso de imprenta sin la voluntaria intervención del copista, de modo que este parámetro no puede contribuir a definir cuál es la más cuidada y fiable de las dos 
ediciones. Las erratas de $A$ son cojines: cof(s)ines (v. 92), parecer: parecər (v. 281), materia: matetia (v. 1281), vengan: vengen (v. 1701), agora: ogora (v. 2027). Las erratas de $B$ son cojines: cof(s)ines (v. 92), mandarme: mandarms (v. 985), tanta: tauta (v. 2090), ellos: ell (v. 2475), escucharlos: escuchar | os (v. 2531), tuviera: tuiera (v. 2619).

\section{UNA PROPUESTA DE EDICIÓN DE LA ENCOMIENDA BIEN GUARDADA COMO VOLUNTAD DEFINITIVA DEL AUTOR}

El texto base que elegí para mi edición ${ }^{15}$ fue el que recoge el manuscrito autógrafo conservado en la Biblioteca Nacional de Madrid (Ms. Vitr. 7-16), por su indudable valor y fiabilidad, siendo testimonio cuya autoría conocemos con seguridad; pero por supuesto, en este caso, no basta con decir esto. Dada la peculiaridad del testimonio, con sus tachaduras y los dos textos que presenta, debo añadir que el texto elegido fue el de La encomienda bien guardada. Como más arriba se anunciaba, en mi edición adopté las siglas $\mathrm{O}^{1}$ para definir la primera redacción de la comedia, La buena guarda (que cuenta con 2931 versos), y O para identificar el texto de $L a$ encomienda bien guardada, que representaría, en mi opinión y por las razones que a continuación se exponen, la voluntad definitiva del autor: el texto de $\mathrm{O}^{1}$ corregido (autocensurado) y ampliado con veintinueve versos interpolados (un total de 2960 versos).

Hay varias razones de peso para reconsiderar este texto, que los editores modernos han relegado sistemáticamente al olvido por tratarse de una versión «censurada». Para empezar, tal consideración de versión censurada tendría que ser revisada. En primer lugar, la autoridad y autenticidad de las intervenciones correctoras es incuestionable: responden al propio Lope de Vega. Se trataría así, como mucho, de un caso de autocensura. La inmediatez de esas correcciones al propio proceso de escritura (no hay signos de cancelación de mano del censor que sí se encuentran en otros autógrafos de Lope), nos llevan a pensar en una autocensura

15 La solución de Capoia parece incuestionable en una presentación en papel. Sin embargo, obsérvese que el lector debe manejar varios aparatos para entender bien todo el proceso, para collegare $i$ dati in sistema, tal como requería de una edición crítica Contini. Para lograr ese objetivo, sin duda la presentación electrónica ofrecería más posibilidades y mejores resultados: véase en este mismo número lo dicho por Valdés. Nota de los editores. 
previa a la acción censoria establecida por instancias oficiales. Según ya ha quedado dicho más arriba, se trataría de una autocensura hasta cierto punto libre de presiones externas: en esta línea iban las conclusiones de Juliá Martínez en la cita recién aportada.

Se podría concebir, entonces, que La encomienda bien guardada representaría, frente a La buena guarda, la «última voluntad» del autor. Nos encontraríamos ante una de las situaciones previstas por Luigi Firpo en su magistral artículo sobre las «Correzioni d'autore coatte», fundamental, en el ámbito de la «filologia d'autore», para decidir cómo actuar en casos donde encontramos censura en variantes (o correcciones) de autor. Firpo apunta que cuando

non si tratta di tagli puri e semplici, ma di adattamenti, spostamenti, attenuazioni, rifacimenti, talvolta perfino di aggiunte interpretative ed esplicative, di fronte alla prima stesura libera e coraggiosa, la seconda attutita può tuttavia presentare rielaborazioni spontanee, non imposte dalla censura [...] In casi del genere mi sembra più saggio attenersi a quella che fu l'ultima volontà dell'autore e [...] collocare a piè di pagina, con evidenza maggiore di quella che si concede di solito alla congerie degli apparati, le varianti originali sacrificate (Firpo 1961:154).

En segundo lugar, hay que considerar que, dado que algunas de las tachaduras de la versión de La buena guarda resultan ilegibles y las restituciones se deben a manos ajenas a Lope, como muy bien apunta Paloma Cuenca [2006:103], «la única redacción completa que tendríamos en la actualidad autógrafa de Lope de Vega es la segunda [O, La encomienda bien guardada], puesto que la restitución de la primera se debe a otra mano, y sin esas restituciones es imposible recomponer el texto completo de la primera versión». De hecho, cabe preguntarse si alguna de esas restituciones podría incluso no ser fiable, no ser auténtica. ${ }^{16}$

16 Paloma Cuenca [2006:101] comenta lo siguiente: «En su mayor parte, los pasajes tachados son ilegibles, como reconocen incluso los editores modernos. Así, afirma P. Díez (ed. cit., p. 24): "No siempre, a pesar de lo dicho por Hartzenbusch y Menéndez Pelayo, puede leerse bien lo borrado, al menos en una lectura rápida, y en estos pocos casos hemos preferido seguir la lección de Hartzenbusch, advirtiéndolo en las notas, o subrayándolo". Este proceder es, sin duda, incorrecto porque añade al texto original, conservado en las dos redacciones del autógrafo, lecturas inventadas y espúreas que se suman a la tradición textual sin necesidad alguna, según era práctica habitual en la filología decimonónica que, lamentablemente, ha perdurado en muchas comedias de Lope». Nota de los editores. 
En tercer lugar, también se debe tener presente que no solo en el momento de la representación, previo a la censura oficial, Lope decidió retocar su texto, sino que además, ese texto revisado, el de La encomienda bien guardada, volvió a ser "autorizado" por el propio Lope un tiempo después, cuando decide que sea ese el que vaya a las prensas. Recuérdese que desde la Parte novena (1617) la publicación de las partes de comedias está bajo el control de Lope y muy probablemente él o personas cercanas a él son quienes hacen llegar sus manuscritos a la imprenta. ${ }^{17}$ De hecho, como se ha visto algo más arriba, tenemos indicios de que el original que se envió a la imprenta pudo tener una relación muy estrecha con el manuscrito autógrafo del que nos venimos ocupando. En fin, La encomienda bien guardada fue el texto validado por el poeta para imprimirse, como subraya Paloma Cuenca [2006:102]. Maria Grazia Profeti también ha insistido una y otra vez sobre el papel validador de los impresos como reflejo de la «última voluntad» del autor. Plantea Profeti:

Delante de versiones distintas ¿qué criterio tendrá que guiarnos? Obviamente el de la voluntad del autor, principio que siempre ha fundado las operaciones ecdóticas; podremos a lo mejor distinguir entre «variantes sustitutivas» y «correcciones instaurativas», según una acertada distinción de Contini. [...] En el caso de redacciones anteriores a las impresas por los mismos autores, es la definitiva versión impresa la que merece ser reproducida; y se tendrán que considerar como borradores las versiones primitivas, dignas naturalmente de estudio como todas las variantes de autor, pero solo como una etapa intermedia hacia el texto definitivo, logrado por el autor con la última reelaboración (Profeti 1996:138 y 140).

Aunque esta línea de argumentación de Profeti, que viene sosteniendo durante los últimos veinte años, ${ }^{18}$ ha sido respondida por algún estudioso, que juzga arriesgado privilegiar la versión de un impreso sobre el propio manuscrito autógrafo, nótese que aquí no es tal la disyuntiva que se plantea: el argumento de la impresión como «última voluntad» del autor, como texto-variante «instaurativo», nos ayuda solo a elegir una de las versiones que en el mismo manuscrito autógrafo se recogen.

17 Véanse Moll [1995] y Dixon [1996].

18 La misma filóloga alude al primer planteamiento de esta línea en las páginas preliminares a la edición de Los donaires de Matico de Marco Presotto [1994:IX-XVII], revisadas y ampliadas posteriormente (Profeti 1996b). En una reciente intervención con ocasión de unas jornadas sobre «La comedia española en la imprenta catalana» (11-12 de abril de 2013) abordaba desde la misma óptica el caso de El castigo sin venganza, con testimonio manuscrito autógrafo y con una suelta seguramente impresa por iniciativa del poeta. 
En definitiva, atendiendo a los distintos argumentos aportados, parece más que justificado, frente a la tendencia unánime de los editores modernos de relegar el texto de La encomienda bien guardada al olvido, exhumarlo, editarlo y elegirlo incluso como texto base para una edición, tal como proponía en mi tesis de licenciatura de 2004, sobre todo si se recogen también en aparato crítico (genético), como proponía entonces, las variantes de la versión anterior, La buena guarda. Nuestro texto base tendría que ser, pues, La encomienda bien guardada, la que consideramos versión definitiva de las que incluye el manuscrito autógrafo y que viene a coincidir y ser sancionada con la que se recoge en la tradición impresa (Decimoquinta Parte de las comedias de Lope de Vega Carpio, en sus dos ediciones de Madrid, 1621). En cuanto a las ediciones modernas tuve especialmente presentes el texto editado por Juliá Martínez [1934] y la tesis doctoral de María del Carmen Artigas (University of Virginia, 1990), ${ }^{19}$ pues cuando yo realicé mi edición todavía no se disponía de la edición de Francisco Crosas [2009].

Cómo recoger adecuada y claramente todo el proceso genético del texto, las variantes y correcciones autocensorias de autor, así como las de la tradición impresa, fue todo un reto, y debo agradecerle al profesor Marco Presotto su ayuda en este aspecto. Concebimos así la elaboración de un doble aparato crítico: puse en el primer apartado una anotación negativa que daba cuenta de lo que ocurrió en el texto cuando el poeta intervino para censurar la primera versión de la leyenda y las relativas intervenciones in itinere (aparato genético); el segundo aparato es positivo, puesto que lleva a la vez la lección del manuscrito y las variantes de los testimonios impresos $A$ y $B$ (evolutivo). Decidí asimismo conservar en el aparato la grafía original y procedí con el método sintético según lo que sigue, adaptando las normas de transcripción de manuscritos de François Masai [1950]:

$<$-abcdef $>$ texto tachado

$<-\ldots>$ texto tachado ilegible

$<$-abc + def $>$ texto tachado corregido sobrescribiendo

$<$-abc \def $>$ texto tachado corregido arriba

$<$-abc / def $>$ texto tachado corregido abajo

$<$-abc $\backslash \backslash$ def $>$ texto tachado corregido al margen izquierdo

$<$-abc // def $>$ texto tachado corregido al margen derecho

19 Para la actualización en este artículo se han comprobado también los loci critici en la edición de 2002: no se introdujeron variaciones. Nota de los editores. 
Al texto de la comedia, para cuya transcripción me atuve a los Criterios del grupo Prolope, le sigue un apartado de notas complementarias (p. 104), para explicar palabras o pasajes dudosos de tipo lingüístico-semántico, y un apéndice de las intervenciones in itinere (p. 119) que se produjeron en el acto de la composición de la pieza en su forma originaria $\left(\mathrm{O}^{1}\right)$.

Aparte de la posibilidad de la consulta de mi edición en línea, se ofrecen aquí reproducidas tres páginas, donde se pueden observar un par de pasajes del texto con la resolución de los aparatos críticos y el apéndice de las intervenciones in itinere. 
ApÉNDICE: TRES PÁGINAS DE MUESTRA DE LA EDICIÓN

PASAJE 1:

Doña Clara ¿Qué cosas tan enfadosas!

CARrizo ¿Celos?

Doña Clara No.

CARrizo

Doña Clara

CARRIZO

FELIS

CARrizo

Doña Clara

CARrizo

$$
\text { ¿Qué? }
$$

Pensamientos.

Digo que no vamos ya, y si buscas gente fea, pasémonos a Guinea, que no habrá celos allá, porque en Mandinga y en Zape nunca han entrado los celos sino es que quieren los cielos que dellos nadie se escape. ¡Vamos a Francia o París! ¡O qué famosa ciudad! Y de mayor libertad que todas las que decís, porque la gran confusión de grandeza y forasteros, de tratos y de extranjeros, causa de tenerla son.

Es bellísima en extremo. Apresta, y vamos allá, aunque en todo el mundo habrá, el mismo temor que temo.

FeIts

A Genovas puedes ir, que es un jardín en la tierra.

mas no podremos vivir
sin que quién somos se entienda.

1638 <-Pues \Digo que> no bamos <-a Toledo> ya

1641 <-viuirás perdido el miedo \\que no abrá // çelos allá>

1646 <-Pardiez> vamos <-a Seuilla // a Françia o París>

1649 que <-las que tiene Castilla // todas las que decis>

$1652<$-de nabes $\backslash \backslash$ de tratos> y de estrangeros

1656 aunque en tod<-a España abrá + o \el mundo abrá>

1658 a <-Valencia \Genobas $>$ puedes yr

1657 temo: tengo $A$

1658 Genovas: Génoua

$A B$ 
PASAJE 2:

\section{Doña Clara}

FELIS

CARrizo

FELIS

Carrizo

Doña Clara

Carrizo

Doña Clara

Carrizo

FELIS

Doña Clara

Carrizo

Doña Clara

[f.35r]

ÁNGEL ciudad que la mar corona

por su más querida prenda;

1665

que por ella Vinarrós

a España podéis pasar.

Amor no suele dudar muramos juntos los dos.

Vamos a cualquiera parte.

1670

Donde quisieres camina, si tu recelo imagina

que tu padre ha de buscarte.

Las mulas están a punto

y la cena.

Pues ¿qué esperas?

1675

Que partas, y que tú quieras.

Por el lugar te pregunto.

Habrá dos leguas, no más.

Pues pica.

¡Lindo camino, adonde pernil y vino

no pueden faltar jamás!

¿No vas contenta, mi amor?

Pues no.

Caminemos presto.

Algún cuidado me ha puesto

lo que me dijo el pastor.

1685

Váyanse

Entren el ángel ya en figura de doña Clara y don Carlos

Yo os prometo de hacer mi diligencia

y persuadir mi padre a vuestro gusto;

$1666<$-o podéys por $\backslash \backslash$ que por ella> Vinarros

1667 <-passar a Ytalia o por ella \\a España podéis passar>

1668 <-Todo el> amor <-lo atropella // no suele dudar>

1670 Vamos a qualquier <-lugar // +a parte>

1671 <-Haçia Toledo camina // Donde quisieres camina>

$1672<-$-o Valençia, si $\backslash \backslash$ si tu reçelo> ymagina

$1673<$ <-Clara que la $\backslash \backslash$ que tu padre> ha<-n> de buscar <+te> mas la palabra habéis de darme luego

de no poner las manos ni la espada 


\section{APARATO DE LAS INTERVENCIONES IN ITINERE DE $O_{1}$}

En este apéndice se reúnen todos los pasajes que he identificado, con cierta seguridad, como intervenciones in itinere del autor, o sea las que se produjeron en el momento mismo de la redacción del texto originario (la primera versión llamada $\left.\mathrm{O}_{1}\right)$.

$\begin{array}{ll}\text { v. } 1252 & \text { si vi<-n>ene a conparaçión } \\ \text { v. } 1267 & \text { <-del> fue sienpre la buena guarda } \\ \text { v. } 1287 & \text { en <-materia de m> dineros y mugeres } \\ \text { v. } 1305 & \text { <-respu> tantos peligros resultan } \\ \text { v. } 1311 & \text { e<-i +n> más de una ynformaçión } \\ \text { v. } 1335 & \text { <-y pareze santo> o trae el nonbre postizo } \\ \text { v. } 1360 & \text { le supli<-q>ca que se llegue } \\ \text { v. } 1376 & \text { D.CA. <-Ginés } \backslash \text { Hermano> ay lugar agora } \\ \text { v. } 1406 & \text { <-mientras> sino es q el sol se para } \\ \text { v. } 1437 & \text { <-quando por su> / con el anillo q a la vista excede } \\ \text { v. } 1451 \text { Acot } & \text { <-CARRizo> Siéntense. } \\ \text { v. } 1485 & \text { <-deçiende> q por tu obeja se te abrasa el pecho } \\ \text { v. } 1497 & \text { más no ay lirio en el <-...rco } \backslash \text { prado> ni amapola } \\ \text { v. } 1542 & \text { CLA. Sudaba de <-bus> cansado } \\ \text { v. } 1554 & \text { las abarcas <-tenía> de pieles } \\ \text { v. } 1555 & \text { Sigue verso tachado: <-más rica q doseles> } \\ \text { v. } 1604 & \text { <-el } \backslash \backslash \text { buen> color sabor y olor } \\ \text { v. } 1611 & \text { <-d+con>fortan y recuperan } \\ \text { v. } 1675 & \text { Sigue verso tachado: <-q dexe el sol > } \\ \text { v. } 1688 & \text { mas la palabra<-s> habéys de darme luego } \\ \text { v. } 1701 & \text { vengan los agrabi<-os +ados> y assí dize } \\ \text { v. } 1711 & \text { el que pidiere a dios de <-sus ene> quien le ofende } \\ \text { v. } 1730 & \text { Clara q las estrellas <-esclarezes> escurezes }\end{array}$




\section{BIBLIOGRAFÍA}

Artelope: Oleza, Joan et al., Base de Datos y Argumentos del teatro de Lope de Vega. ARTELOPE [en línea en http://artelope.uv.es]. Consulta del 5 de enero de 2014.

Artigas, María del Carmen, Edición crítica y anotada de La buena guarda de Lope de Vega, tesis doctoral, University of Virginia, 1990.

Artigas, María del Carmen [2002]: veáse Vega Carpio, Lope de, La buena guarda.

Blecua, Alberto, Manual de crítica textual, Editorial Castalia, Madrid, 1990.

CAPOIA, Stefania, Edición crítica de La encomienda bien guardada de Lope de Vega, "tesi di laurea» presentada en la Università Ca'Foscari de Venecia en el año 2005 (curso académico 2004 / 2005). Consulta en línea: https://ddd.uab.cat/ record/115161, consultado el 29 de enero de 2014.

CRIVELlari, Daniele, Marcas autoriales de segmentación en las comedias autógrafas de Lope de Vega: estudio y análisis, Edition Reichenberger, Kassel, 2013.

Crosas, Francisco [2009]: veáse Vega CARPIo, Lope de, La buena guarda.

Cuenca Muñoz, Paloma, «Estudio paleográfico de algunos autógrafos teatrales de Lope de Vega y edición del entremés de Melisendra (Res. 88)», Cuadernos para Investigación de la Literatura Hispánica, XXIV (1999), pp. 149-193.

Cuenca Muñoz, Paloma, «La edición paleográfica de textos teatrales clásicos: La encomienda bien guardada de Lope de Vega", en V Jornadas Científicas sobre Documentación de Castilla e Indias en el siglo XVII, dir J. Galende Díaz, Universidad Complutense de Madrid, Madrid, 2006, pp. 93-103.

Díez y Giménez Castellanos, Pilar [1964]: veáse Vega Carpio, Lope de, La buena guarda.

Dixon, Victor, «La intervención de Lope en la publicación de sus comedias», Anuario Lope de Vega, II (1996), pp. 45-63.

FIRPo, Luigi, "Correzioni d'autore coatte», en Studi e problemi di critica testuale, Commissione per i testi di lingua, Bolonia, 1961, pp. 143-157.

Hartzenbusch, Juan Eugenio [1857]: veáse Vega Carpio, Lope de, La buena guarda. Juliá Martínez, Eduardo [1934]: veáse Vega Carpio, Lope de, La buena guarda.

Masai, François, «Principes et conventions de l'édition diplomatique», Scriptorium, IV (1950), pp. 177-193.

Menéndez Pelayo, Marcelino [1895]: veáse Vega Carpio, Lope de, La buena guarda. Moll, Jaime, «Los editores de Lope de Vega», Edad de Oro, XIV (1995), pp. 213-222. 
Presotto, Marco, ed., Lope de Vega, Los donaires de Matico, Reichenberger, Kassel, 1994.

Presotto, Marco, Le commedie autografe di Lope de Vega. Catalogo e studio, Edition Reichenberger, Kassel, 2000.

Profetr, Maria Grazia, La Collezione Diferentes Autores, Edition Reichenberger, Kassel, 1988.

Profeti, Maria Grazia, «Editar el teatro del Fénix de los ingenios», Anuario Lope de Vega, II (1996), pp. 129-151.

Profeti, Maria Grazia, «Comedias representadas / textos literarios: los problemas ecdóticos», en Teatro, historia y sociedad, Seminario internacional sobre teatro del Siglo de Oro, Universidad de Murcia-Universidad Autónoma de Ciudad Juárez, 1996, pp. 207-216.

VEGA, Lope de, La buena guarda, en Comedias escogidas de Frey Lope Félix de Vega Carpio, ed. J. E. Hartzenbusch, Rivadeneyra (BAE, XLI), Madrid, 1857, pp. 325-344.

VEGA, Lope de, La buena guarda, en Obras de Lope de Vega publicadas por la Real Academia Española, ed. M. Menéndez Pelayo, Madrid, 1895, V, pp. 315-360.

VEGA, Lope de, La buena guarda, en Obras dramáticas escogidas, ed. E. Juliá Martínez, Librería y casa editorial Hernando, Madrid, 1934, I.

VegA, Lope de, La buena guarda o La encomienda bien guardada, ed. P. Díez y Giménez Castellanos, Biblioteca Clásica Ebro, Zaragoza, 1964.

VeGA, Lope de, La buena guarda, ed. M. del C. Artigas, Verbum, Madrid, 2002.

VEGA, Lope de, La buena guarda, ed. Francisco Crosas [en línea en http://humanidadestoledo.uclm.es/documentos/lope-buena.pdf]. Consulta del 1 de enero de 2014.

Vega, Lope de, Decimoquinta Parte de las comedias de Lope de Vega Carpio, Fernando Correa de Montenegro, a costa de Alonso Pérez, Madrid, 1621.

VEGA, Lope de, Decimoquinta Parte de las comedias de Lope de Vega Carpio, Viuda de Alonso Martín, a costa de Alonso Pérez, Madrid, 1621.

VEGA, Lope de, La encomienda bien guardada, Madrid, 16 de abril de 1610, manuscrito conservado en la Biblioteca Nacional de Madrid, signatura Vitr. 7-16. 